\title{
On the Path Rooted in the Combination of School Education and National Traditional Culture Education
}

\author{
Dechuan Qi \\ Office of Yunnan Minority Language Guidance Committee, Kunming 650031, China \\ Email: qdc0871@sina.com
}

\begin{abstract}
The prosperity of a country and a nation is always supported by the prosperity of the culture. The great rejuvenation of the Chinese nation requires the development and prosperity of its traditional culture. To promote the traditional culture of the Chinese nation, we must follow the path of combining school education and traditional ethnic culture education, give play to the role of the main channel of the classroom, and disseminate knowledge of traditional ethnic culture to students.
\end{abstract}

Keywords: take root, school education, customs, traditional culture

\section{Introduction}

China is a multi-ethnic country. In the thousands of years of production and life, people of all ethnic groups have created unique and colorful national cultures, left many outstanding cultural heritages, and formed the traditional culture of the Chinese nation. However, the work of entering the campus for ethnic cultures in ethnic minority areas is still blank, and students know little about the traditional culture and history of their ethnic groups and cannot carry out effective inheritance and development.

\section{The rich connotation of national traditional culture}

The traditional culture of various nationalities refers to the culture with distinctive national characteristics created by the nations living in different regions and their ancestors and inherited and developed for generations by generations. With a national spirit that loves their country as the core, Humanity care as the core value subject and harmonious life as the core of social practice, including the spirit of self-improvement, the rise and fall of the country, the responsibility of everyone, the unity of knowledge and action, the moral consciousness of distinguishing right from wrong, gratitude, conscience, honest and trustworthy man quality, the pursuit of truth, the spirit of devotion, the spirit of solidarity, solidarity and mutual respect, respect for the social morals of the old and the young, pay attention to the spirit, and reconstruct the spiritual education spirit. ${ }^{[1]}$

The spirit of national traditional culture is a spirit, a belief, a state that supports the Chinese nation's independence in the forests of the world's nations. It is the endless blood flowing in the blood vessels of the Chinese nation, and it is passed down from generation to generation. Handed down. For the independence and prosperity of the country, for the freedom of the nation, and for the happiness of the people, a song of patriotism resounding through the sky has been composed, and it has become a powerful spiritual pillar of the nation and an invincible great force. ${ }^{[2]}$ It is practice to discover truth, and to test truth, confirm truth, and develop truth through practice. The courage to dedicate to the consciousness of thinking is the outstanding traditional virtue of all Chinese nations, and it is also the most important cultural tradition of all nations.

\section{The importance of combining school education with traditional cultural education of ethnic minorities}

National traditional culture is an indispensable part of Chinese culture. The culture of all ethnic groups in China is deeply rooted in the fertile soil of Chinese civilization, which not only promotes the development of traditional cultures of various ethnic groups, but also enriches the connotation of traditional Chinese culture.

First, national traditional culture is the core, soul and source of the national spirit. ${ }^{[3]}$ The traditional culture of various nationalities is the essence that has been precipitated during the thousands of years of historical evolution. It is a reflection of national characteristics and features brought about by the evolution of civilization. The ideological spirit of all Chinese nations is the foundation of social politics and economy, and it is the core, soul and source of the national spirit. 
Second, national traditional culture is the spiritual bond that sustains the survival and development of various nationalities. Traditional culture is the precious spiritual wealth of a nation and the spiritual bond that sustains a nation's survival and development. The influence of traditional cultures of various nationalities on society is twofold. Inheriting traditional culture must also "take the essence and remove the dross", critically inherit it, and use it for the past.

Third, national traditional culture is the memory of a nation and a shared spiritual home. The traditional culture of all nations is the soul and blood of a nation, the collective memory and spiritual home of a nation, reflects the sense of identity and belonging of the nation, reflects the vitality and cohesion of a nation, and is shared and shared by the people of a nation Their wealth is also the bond that connects their hearts. ${ }^{[4]}$

Fourth, the national traditional culture has the important value of cultural diversity. The power of traditional cultures of various nationalities is deeply rooted in the vitality, creativity, and cohesion of the Chinese nation. The long-standing and profound Chinese traditional culture of various nationalities has had a profound impact. Respect for cultural diversity is an inherent requirement for the development of the cultures of various nationalities, an inevitable requirement for the prosperity of the Chinese nation's culture, and has its important value.

The traditional cultures of various ethnic groups include patriotism, ethics, truth-seeking, harmony, and doctrine. They reflect the sense of identity and belonging of a nation, and reflect the vitality and cohesion of a nation. In terms of sexuality, symbiosis, and commonality, it points to the historical identity of the Chinese nation, the psychological identity of the members of the Chinese nation, and the value identity of the Chinese culture. It promotes and bolsters the sense of the Chinese nation community with the promotion of the excellent traditional Chinese culture. ${ }^{[5]}$

\section{Feasibility of national traditional culture education}

As a long-term project and soul-casting project, traditional ethnic culture education runs through the entire process of national talent training, and is integrated into the entire country, including ethnic regions, in the school textbook system. The traditional ethnic culture education is regarded as the foundation project of the entire country.

First, schools play a major role. For a long time, school education in ethnic areas has played an important role in inheriting and developing national traditional culture. ${ }^{[6]}$ School education in ethnic areas and the development of national traditional culture are mainly achieved through the organization of bilingual teaching, the development of local teaching materials, and the introduction of folk artists into the classroom. Schools have traditionally put ethnic traditional culture as an important part of education, and organized and implemented it.

Second, the family plays a key role. Ethnic traditional culture will enter the school, and the "trinity" of the traditional culture of the school, family and society will be inherited and educated. Focusing on the popularization of family virtue education, the school will launch a "book family" selection activity. Guide parents to learn traditional culture, comprehend the essence of traditional culture, pay attention to preaching by example, and improve parents' ability to use traditional culture to carry out family education. ${ }^{[7]}$

The third is the role of society as a platform. Organize, plan, and carry out education on national traditional culture and traditional virtues. Open some public welfare facilities, such as museums, former residences of celebrities, and various memorials, free of charge to young people, and strengthen the construction of youth activities such as the Youth Palace and Youth Center.

Fourth, teachers play a guiding role. Schools at all levels and at all levels should dig deep into traditional ethnic culture, and schools should offer traditional ethnic culture courses (including tutoring courses, reading instruction courses, etc.). Thematic education is provided through various activities such as theme team meetings, story meetings, lectures, and lectures.

\section{The practice path of national traditional culture education}

Taking Baisha Wanxiao in Baisha Town, Yulong County, Lijiang City, Yunnan Province as an example, the school has gradually established a multi-dimensional, three-dimensional teaching model of traditional ethnic culture education.

Naxi language class. The school adopts the two-way teaching method of Naxi language and Chinese language. From the first grade, teachers use Naxi language and Chinese language for teaching. Students can not only master some national language knowledge in a more systematic way, but also deepen their national cultural knowledge. ${ }^{[8]}$

Dongba language lesson. Dongba script is the essence of Naxi traditional culture and the crystallization of the wisdom of ancient Naxi people. It is the only living hieroglyph in the world today, and it is of great significance to study the beginning and development of Naxi and even human civilization. Starting from the third grade, each class has one Dongba 
language lesson per week. ${ }^{[9]}$

Baisha fine music lesson. Baisha Xile is praised as "living music fossil" and at the same time has been awarded the "Precious Cultural Heritage of All Humanity" by UNESCO. The school guarantees one and a half hours of fine music teaching time on Monday, Wednesday, and Friday, and teaches music theory to students on Tuesday and Thursday.

Dongba dance class. Dongba dance, also known as Dongba dance, is a dance performed by more than 60 Dongba shamans recorded in the "Dong Mo" (the meaning of the dance spectrum) in the Dongba Sutra written by the ancestors of the Naxi people. In order to inherit the traditional culture of the Naxi nationality, the school excavated and organized a set of students teaching dance from the local community. The school specially hired Baisha Dongba artists as Dongba dance teachers to teach once a week.

Naxi Paper Cutting Class. Paper-cut art is one of the outstanding representatives of Naxi folk culture, and it is one of the traditional handmade arts with the most Naxi national characteristics. In order to inherit the art of paper-cutting of the Naxi people, Bai Shawan primary school is in the first to sixth grades. Each class provides one class per week and uses the school's self-made teaching materials.

Folk art class. The most distinctive feature of the Naxi folk art is the ancient Dongba painting. It is a Naxi folk art heritage and an important part of Dongba culture. ${ }^{[10]}$ Folk art is based on Dongba art, and is developed according to the characteristics of students' aesthetics and beauty, and has achieved good results.

\section{Conclusion}

The campus is the main implementation base of education and the main place to inherit national traditional culture, and the students are also the main group for the acceptance and inheritance of traditional culture. The need for development is the need to train students to become talented ${ }^{[11]}$ and to let the Chinese traditional culture penetrate into the hearts of children, and inspire the children to have and love the emotions of excellent traditional culture.

\section{References}

[1] Zhang Jinfeng. On the Inheritance and Development of Traditional Chinese Culture. Climbing: Philosophy and Social Science. 1999; 5: 78-81.

[2] An Kejie. The Unified Thought of Moral Education, Knowledge and Action in Chinese Traditional Culture. Mountain Flowers. 2008; 9: 31-31.

[3] Sun Dengyong. Honest and trustworthy, pretend to be the heart of others. Rural Mass News. 2019; 11.

[4] Zhou Hong, Zhao Huapeng. A New Probe into the Dialectical Relationship between Relative Truth and Absolute Truth. Journal of Xi'an University of Architecture and Technology: Social Science Edition. 2005; 1: 22-25.

[5] Wang Jinyou. Unity, Mutual Assistance, Unity. Practice (Ideological and Theoretical Edition). 2006; 22-25.

[6] Yang Junchang. The main purpose of contemporary education culture is to reshape the spirit, rebuild features, rebuild literacy and improve. Education and Culture Forum. 2010; 5: 1-4.

[7] Zhao Nan, Chen Shijie, Sun Xuefeng. Discussion on Strategies for the Construction of Traditional Culture and Ideological and Political Theory Courses. External School Education in China: The Late Period. 2017; 8: 123-124.

[8] Guo Jianning. Chinese Coordinates for the Rise of Culture. People's Forum 2008; 16.

[9] Zhang Xiaoning. Enhancing the Consensus and Cohesion of the Chinese Nation. Learning Times. 2013.

[10] Cai Shu. How to Promote National Traditional Culture for Contemporary Youth. Examination Weekly 2010; 19.

[11] Cai Jian. Cast the Consciousness of the Chinese National Community. Guangming.com health.gmw.cn/[DB/OL]. 2019.

[12] Liao Hainan, Ding Linghui. Discussion on the Role of Schools, Families, and Society in the Inheritance of Tibetan Traditional Culture. Tibet Education. 2013; 11: 3-5. 